DOI: $10.24850 / j-t y c a-2022-02-09$

Articles

\title{
Stability regions for an explicit numerical solution of the one-dimensional Richards equation applied to water soil infiltration
}

\section{Regiones de estabilidad para una solución numérica explicita de la ecuación de Richards unidimensional aplicada a la infiltración de agua en suelos}

H. Alejandro Pedrozo1, ORCID: https://orcid.org/0000-0002-5732-8985

Mario R. Rosenberger² ORCID: https://orcid.org/0000-0002-7104-8090

Carlos E. Schvezov33 ORCID: https://orcid.org/0000-0001-7601-2073

${ }^{1}$ Instituto de Materiales de Misiones (IMAM) CONICET, Universidad Nacional de Misiones, Misiones, Argentina/Planta Piloto de Ingeniería Química (PLAPIQUI CONICET-UNS), Bahía Blanca, Argentina, apedrozo@plapiqui.edu.ar

2Instituto de Materiales de Misiones (IMAM) CONICET, Universidad Nacional de Misiones, Misiones, Argentina,rrmario@fceqyn.unam.edu.ar 
3Instituto de Materiales de Misiones (IMAM) CONICET, Universidad Nacional de Misiones, Misiones, Argentina, schvezov@fceqyn.unam.edu.ar

Corresponding author: H. Alejandro Pedrozo, apedrozo@plapiqui.edu.ar

\section{Abstract}

Richards equation describes the infiltration and movement of water in porous media, such as soils. This equation, added to the complex constitutive equations which characterize the soil, produces a nonlinear system of partial differential equations. In this work, the Richards equation formulated as a function of the saturation degree was solved by an explicit finite difference method. The matric potential was obtained as a function of the saturation degree, and the convergence of the solutions was analyzed by a modified von Neumann procedure and compared with numerical calculations. As a result, an analytical expression was obtained to determine a priori if a simulation was stable for given time and spatial steps. From those simulation parameters and soils properties, dimensionless numbers were defined to generalize the proposed method.

Keywords: Stability analysis, Richards equation, Porous media, Water infiltration.

\section{Resumen}


La ecuación de Richards se utiliza para modelar la infiltración y el movimiento de agua en suelos, u otro medio poroso. Esta ecuación, junto con las complejas ecuaciones constitutivas que caracterizan al suelo, resulta en un sistema de ecuaciones no lineales en derivadas parciales. En este trabajo, la ecuación de Richards se escribe en función del grado de saturación del suelo, y se resuelve por medio de un método explícito en diferencias finitas. El potencial matricial se obtiene como una función del grado de saturación y la convergencia de las soluciones numéricas se analiza por medio del procedimiento de von Neumann. Como resultado, se obtiene una expresión analítica para determinar si una simulación es estable con pasos temporales y espaciales dados. A partir de estos parámetros de simulación y las propiedades del suelo, se definen números adimensionales para generalizar el método propuesto.

Palabras clave: análisis de estabilidad, ecuación de Richards, medio poroso, infiltración de agua.

Received: 07/02/2019

Accepted: $11 / 04 / 2021$

\section{Introduction}


The mathematical model of fluid movement in unsaturated soil is important in many branches of science and engineering. For example, to study groundwater hydrology, petroleum engineering, and agriculture (Celia, Bouloutas, \& Zarba, 1990; Miranda, Duarte, Libardi, \& Folegatti, 2005; Saucedo, Zavala, \& Fuentes, 2015).

It is common to apply Darcy's law when modeling water flow systems in porous media (Miller et al., 2013; Warrick, 1991), which, combined with the continuity equation, results in the Richards equation (Richards, 1931). This equation is the governing equation for fluid movement in unsaturated soil. It is a strongly nonlinear parabolic partial differential equation; therefore, numerical methods usually are applied to solve it (Berardi, Difonzo, Vurro, \& Lopez, 2018; Caviedes-Voullième, Garcl, \& Murillo, 2013; Gyrya, Lipnikov, Manzini, \& Svyatskiy, 2014; Hills, Porro, Hudson, \& Wierenga, 1989; Romano, Brunone, \& Santini, 1998; Solin \& Kuraz, 2011; Wendland \& Pizarro, 2010). However, considerable attention should be paid to solving Richards equation to get an accurate discretization and an efficient solver (Jeltsch \& Nevanlinna, 1981; Lipnikov, Moulton, \& Svyatskiy, 2016; Miller et al., 2013). Besides, the abrupt change in the value of some parameters like the hydraulic conductivity during the simulation may cause stability problems (Solin \& Kuraz, 2011). 
To reduce the computational time to solve this equation, the numerical time step may be increased, however, this change may increase mass balance error, and the model may not converge. So, a compromise between time step and mass balance error must be made.

Richards equation may be written based on several variables; these include volumetric humidity, matric potential, saturation degree, and different combined forms of these variables. Each expression of this equation presents different discretization forms. The most common expression is based on matric potential. This form does not need constitutive relationships to transform state variables, which allows a direct application of implicit numerical methods. However, it is necessary to approximate the partial derivative concerning time by a Taylor expansion, which introduces an extra error, and thus the model is more sensitive to the time step.

Another form of Richards equation is written as a combination of volumetric humidity and matric potential (Celia et al., 1990). This form does not need a Taylor expansion for the partial derivate with respect to time, and the mass balance errors are lower (Celia et al., 1990; Romano et al., 1998). Nevertheless, complex constitutive relationships are necessary to transform the state variables.

Richards equation can also be written as a combination based on saturation degree and matric potential. Since the saturation degree has a linear relationship with humidity, an accurate relation by Taylor expansion is obtained without introducing additional error in the time derivative. 
Besides, the corresponding constitutive equations based on humidity are simpler than the expressions based on matric potential; therefore, this form can be an advantageous choice to solve the Richards equation by finite difference numerical methods. On the other hand, the analysis of the stability of the numerical methods provides important information about the reliability and robustness of the model. Even more in the Richards equation, which is considered very stiff to numerical integration (Berardi \& Vurro, 2016). If the resulting error for a given discrete algorithm is large enough, the simulation diverges, and the parameters must be adjusted to converge the computational experiment, or the model must be changed in extreme cases (Jeltsch \& Nevanlinna, 1981; Lipnikov et al., 2016; Yuste \& Acedo, 2005).

Although there is no procedure developed to analyze the stability of nonlinear equations, it is possible to linearize or discard low nonlinear terms from the equation and apply a standard procedure for the resulting linear equation (Canelón \& Darío, 2003). This does not apply for the Richards equation that is highly nonlinear (Celia et al., 1990; Romano et al., 1998), and therefore other methods for treating stabilities must be applied.

We have proposed a new approximation method based on a Taylor expansion for the Richards equation and a linearization process to determine a priori if the simulation is stable (Pedrozo, Rosenberger, \& Schvezov, 2016). Thus, this manuscript's main objective is to give more details of both, the approximation method's numerical behavior and the 
stability analysis. We validate the explicit finite difference model based on a combination of two state variables, saturation degree, and matric potential, with a literature case study and perform sensibility analyses for the time and spatial steps. We explain in depth the procedure to obtain the equations to make decisions about the system's stability, and the proposed method was tested by using two case studies of the literature. Furthermore, we address the method's generalization by estimating the stability regions through the main parameters of the simulation.

\section{Computational methods}

\section{Governing equation of the model}

The Richards equation is written as a function of both, saturation degree (Se) and matric potential $(\psi)$, where the $z$ coordinate grows upwards, is shown in Equation (1); and the saturation degree is defined in Equation (2): 
Tecnología y

Ciencias $\stackrel{\unlhd}{\unlhd}$ gua
2022, Instituto Mexicano de Tecnología del Agua

Open Access bajo la licencia CC BY-NC-SA 4.0

(https://creativecommons.org/licenses/by-nc-sa/4.0/)

$\left(\theta_{s}-\theta_{r}\right) \frac{\partial S e}{\partial t}=\frac{\partial}{\partial z}\left(K(\psi)\left(\frac{\partial \psi}{\partial z}+1\right)\right)$

$S e=\frac{\left(\theta-\theta_{r}\right)}{\left(\theta_{s}-\theta_{r}\right)}$

Where $t$ is time; $z$ is depth in the upward direction; $K(\psi)$ is the soil hydraulic conductivity; $\theta_{s}$ is the volumetric humidity of the saturated soil and $\theta_{r}$ is the volumetric residual humidity of the soil. Besides, we used the constitutive equations proposed by Mualem (1976) and modified by van Genuchten (1980):

$K(S e)=K S \cdot S e^{0.5}\left(1-\left(1-S e^{\frac{1}{m}}\right)^{m}\right)^{2}$

$K(\psi)=\frac{K s\left(1-(\alpha|\psi|)^{n-1}\left(1+(\alpha|\psi|)^{n}\right)^{-m}\right)^{2}}{\left(1+(\alpha|\psi|)^{n}\right)^{m / 2}}$

$\psi(S e)=\frac{-1}{\alpha} \sqrt[n]{\sqrt[m]{\frac{1}{S e}}-1}$ 
Where: $\alpha, n$, and $m$ are parameters that depend on the kind of soil and $K s$ is the saturated hydraulic conductivity of the soil.

\section{Numerical model}

We select an explicit finite difference method for the discretization of the Richards equation, where the subscript $i$ indicates the depth (which increases downward) and the superscript $j$ indicates the time (see Figure 1). The equation may be written as:

$S e_{i}^{j+1}=S e_{i}^{j}+\frac{\Delta t}{\Delta z^{2}\left(\theta_{s}-\theta_{r}\right)}\left(K\left(\psi_{i+\frac{1}{2}}^{j}\right)\left(\psi_{i+1}^{j}-\psi_{i}^{j}+\Delta z\right)-K\left(\psi_{i-\frac{1}{2}}^{j}\right)\left(\psi_{i}^{j}-\psi_{i-1}^{j}+\Delta z\right)\right)$

(6) 
Tecnología y

Ciencias ฐ̊Agua
2022, Instituto Mexicano de Tecnología del Agua

Open Access bajo la licencia CC BY-NC-SA 4.0

(https://creativecommons.org/licenses/by-nc-sa/4.0/)

Soil surface

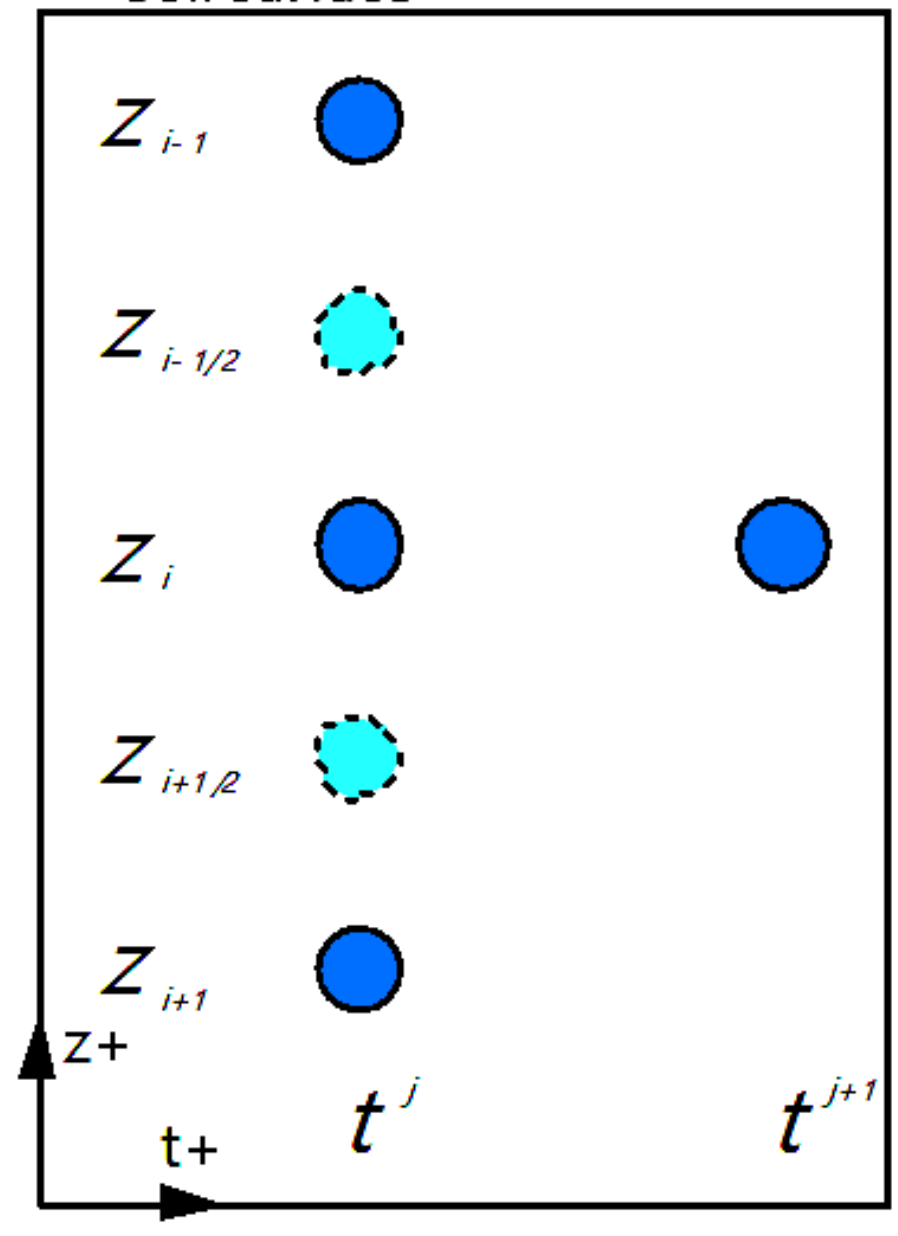

Figure 1. Nodes scheme.

Since Equation (6) is based on both saturation degree and matric potential, Equation (5) is necessary to transform state variables. If an implicit method is used, such transformations are not accurate, and a 
Taylor expansion would be needed. For this reason, an explicit method was selected.

The average hydraulic conductivity showed in Equation (7) describes the flow velocity in steady-state between two nodes at potential $\psi_{i}^{j}$ and $\psi_{i+1}^{j}$. This equation is more accurate than other averages (Schlüter, Vanderborght, \& Vogel, 2012; Szymkiewicz \& Helmig, 2011), and was proposed by Baker (Baker, 2000):

$$
K\left(\psi_{i+\frac{1}{2}}^{j}\right)=\frac{1}{\Delta \psi+\Delta z}\left(\int_{\psi_{i}^{j}}^{\psi_{i+1}^{j}} K(\psi) d \psi+\int_{z_{i}^{j}}^{z_{i+1}^{j}} K(\psi) d z\right)
$$

Equation (7) is composed of two indefinite integrals, one is a function of matric potential, and the other is a function of the spatial step. It is possible to calculate the primitive of the integral that is a function of matric potential due to the relationship between hydraulic conductivity and matric potential is known (see Equation. (8)). On the other hand, calculating the integral in the function of the spatial step is complicated. For that reason, the approximation (9) is used:

$\int K\left(\psi_{i}^{j}\right) d \psi=P K\left(\psi_{i}^{j}\right)$ 
$\frac{1}{\Delta z} \int_{z_{i}^{j}}^{z_{i+1}^{j}} K(\psi) d z=\frac{K\left(\psi_{i+1}^{j}\right)+K\left(\psi_{i}^{j}\right)}{2}$

Introducing equations (7), (8), and (9) in Equation (6) and considering that $K\left(\psi_{i}^{j}\right)=K\left(S e_{i}^{j}\right)$, the result is Equation (10), which is used in the present model:

$$
\begin{aligned}
& S e_{i}^{j+1}=S e_{i}^{j}+\frac{\Delta t}{\Delta z^{2}\left(\theta_{s}-\theta_{r}\right)}\left(P K\left(\psi_{i+1}^{j}\right)-2 P K\left(\psi_{i}^{j}\right)+P K\left(\psi_{i-1}^{j}\right)+\frac{\Delta z}{2}\left(K\left(S e_{i+1}^{j}\right)-\right.\right. \\
& \left.\left.K\left(S e_{i-1}^{j}\right)\right)\right)
\end{aligned}
$$

\section{Calculation procedures}

The whole domain was discretized, and Equation (10) was applied to all the nodes. The calculations were made using a personal computer Intel ( Core $^{\text {TM }}$ i7-3770 CPU@3.50GHz with 8 GB of RAM. We implemented the numerical method in Wolfram Mathematica 9.0, where we used the following modules: 
- Parameter declarations: function definitions and pre-calculations. Particularly, $P K(\psi)$ was calculated by Equation (8) using the "Integrate" command of Mathematica.

- The iteration procedure: due to the problem boundary conditions and the field's initial state, after each time-step there is a change of soil humidity only in the shallowest nodes. So, including all the nodes in the calculation array is not necessary. Therefore, the algorithm identifies the deepest node for which humidity may increase. Let $M$ be the number of nodes with the first node $(i=0)$ located on the surface, and let $M^{\prime}$ be the deepest node that remains in its initial state, such that $M^{\prime}<M$. Therefore, the explicit method is only applied to the subset of nodes $i=0$ to $M^{\prime}$. It should be noted that the value of $M^{\prime}$ changes as iterations proceed. In this way, the number of calculations is reduced. The hydraulic conductivity and matric potential are calculated using Equations 3 and 5, respectively.

\section{Parameters and validation}

To validate the proposed method, we compared our numerical results with the models reported in the literature by Celia et al. (1990) and Wendland 
and Pizarro (2010), considering the same boundary conditions and initial humidity values. The case study was the infiltration of water in sandy soil, which has the following parameters $\theta_{s}=0.368 \mathrm{~m}^{3} / \mathrm{m}^{3}, \theta_{r}=0.102 \mathrm{~m}^{3} / \mathrm{m}^{3}$, $\alpha=3.35 \mathrm{~m}^{-1}, K s=9.22 .10^{-5} \mathrm{~m} . \mathrm{s}^{-1}, n=2, m=0.5$.

At the beginning of the simulation, the soil humidity was low and uniform $\left(0.11 \mathrm{~m}^{3} / \mathrm{m}^{3}\right)$ in the whole domain, while the surface humidity was high and constant $\left(0.20 \mathrm{~m}^{3} / \mathrm{m}^{3}\right)$. The corresponding matric potential initial condition was $\psi(0, \mathrm{z})=-10 \mathrm{~m}$, and Dirichlet boundary conditions of $\psi(\mathrm{t}, 0)=-0.75 \mathrm{~m}$ and $\psi(\mathrm{t},-1)=-10 \mathrm{~m}$. The soil depth was of $1 \mathrm{~m}$ and the simulation time was 1 day.

The present model infiltration profiles and those reported by Wendland and Pizarro (2010) are shown in Figure 2. It was observed that they accurately match since curves overlap. This fact shows that the proposed model can correctly approximate the solution reported in the literature and produces practically the same solution. Moreover, the glo bal error was lower than $1 \%$ and has a maximum local error of $10 \%$, which was located at a depth of $0.60 \mathrm{~m}$ (see Figure 3 ), where the humidity gradient was the largest. These outcomes indicate that the model presented here was a suitable approximation. 
Tecnología y

\section{Ciencias $\stackrel{\Im}{\approx}$ gua}

2022, Instituto Mexicano de Tecnología del Agua

Open Access bajo la licencia CC BY-NC-SA 4.0

(https://creativecommons.org/licenses/by-nc-sa/4.0/)

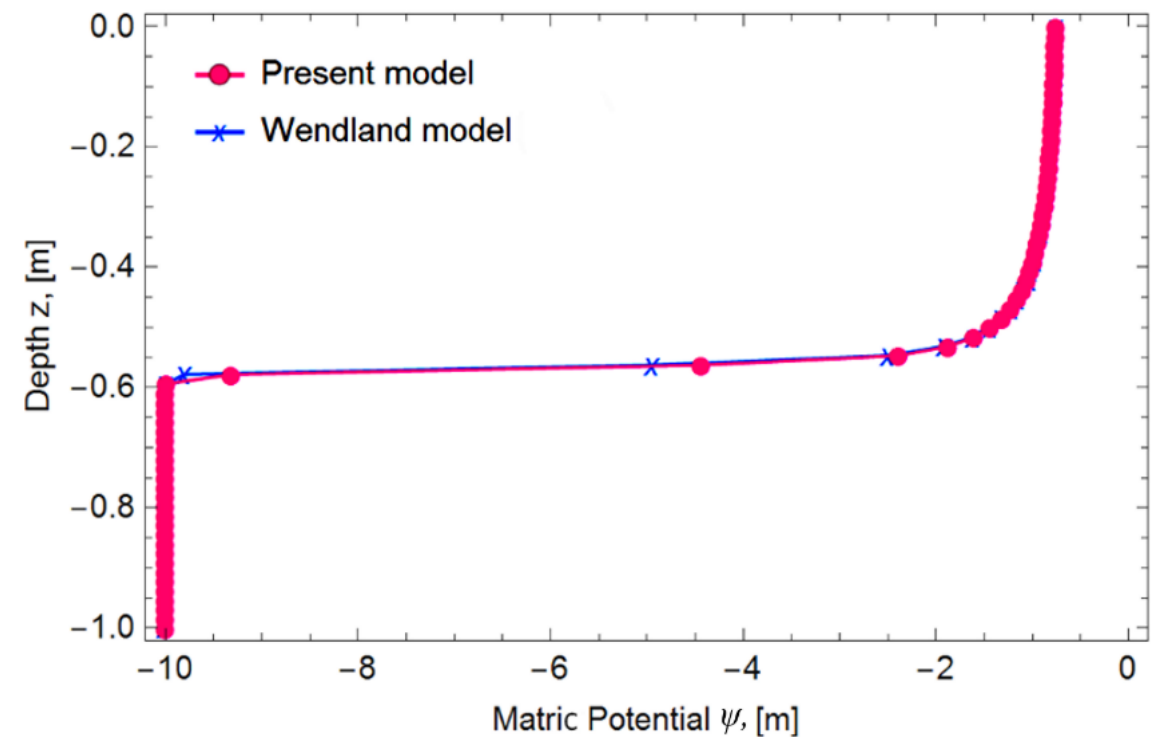

Figure 2. Comparison between results of the present model and the model proposed by Wendland and Pizarro (2010).

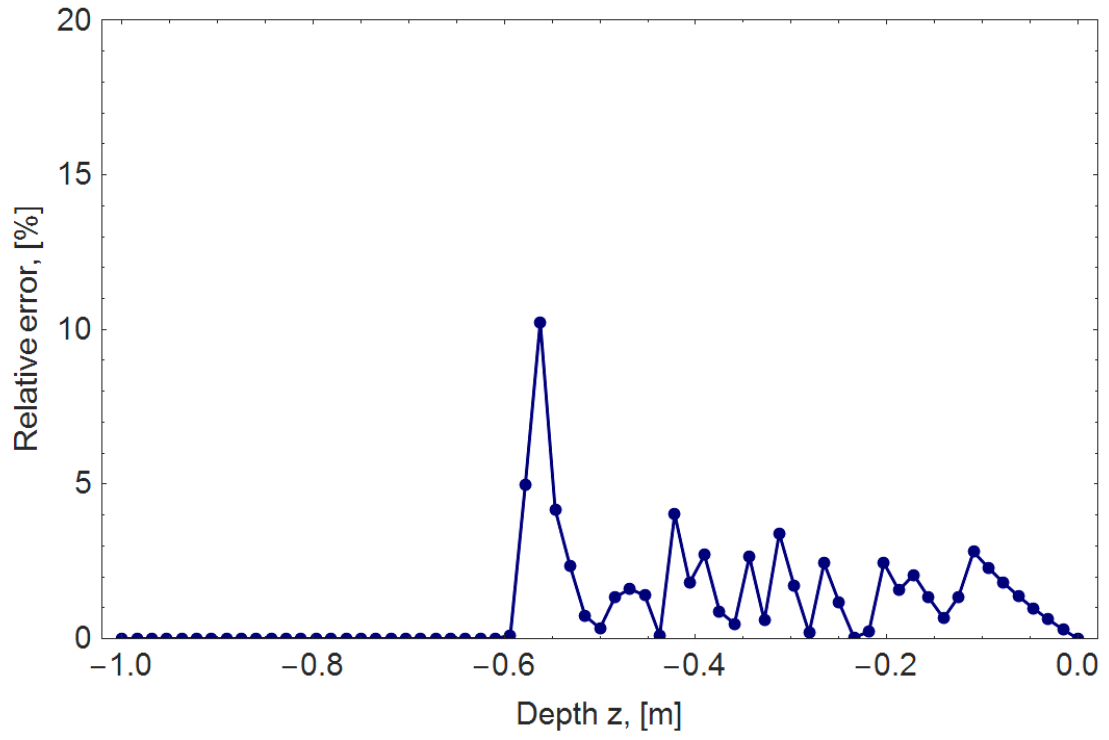

Figure 3. The local error of the present model. 
Tecnología y

Ciencias $₫$ Agua
2022, Instituto Mexicano de Tecnología del Agua

Open Access bajo la licencia CC BY-NC-SA 4.0

(https://creativecommons.org/licenses/by-nc-sa/4.0/)

\section{Sensitivity analysis}

\section{Effect of the time step, $\Delta t$}

The first step of the analysis was to quantify the results errors as a time step function. One simulation was chosen as a reference, which solution is considered as the true value. Therefore, relative errors of simulations with other parameters were calculated by comparison. The reference simulation was obtained with the proposed model when the simulation time is one day and the time step is one second, which is considered small enough to make the temporal discretization errors negligible. To make the comparison, the highest local error was used, which was included in Equation (11):

$\operatorname{Max}\left(\left|\frac{\psi_{i}^{\text {tmax }}-\psi v_{i}^{\text {tmax }}}{\psi v_{i}^{\text {tmax }}}\right|\right)$ 
where $\psi v_{i}^{\text {tmax }}$ is the matric potential obtained by the proposed model with a time step of one second, while $\psi_{i}^{\text {tmax }}$ is the matric potential obtained with the highest time step. Different spatial steps were considered for the analysis, $-1 / 40 \mathrm{~m},-1 / 64 \mathrm{~m}$, and $-1 / 80 \mathrm{~m}$. Therefore, each spatial step has a different reference simulation to make the comparisons.

The results are shown in Figure 4, for the three spatial steps, and a wide range of time steps, from 1 to 54 seconds. A linear relationship between maximum relative error and time step was observed, with a maximum error of $0.85 \%$. In addition, the maximum relative error, with a time step of 1 second, is $0 \%$ for each spatial step, in such case, this time step was taken as reference. In Figure 4 , for a spatial step of $-1 / 80$ $\mathrm{m}$, the model becomes unstable and diverges for time steps larger than $34 \mathrm{~s}$ for a reason that is discussed in the next section. On the other hand, by comparing the lines slopes, it was observed that the slope changes among them diminish when the absolute value of the spatial step diminishes; this indicates that the method is convergent for the spatial step. 


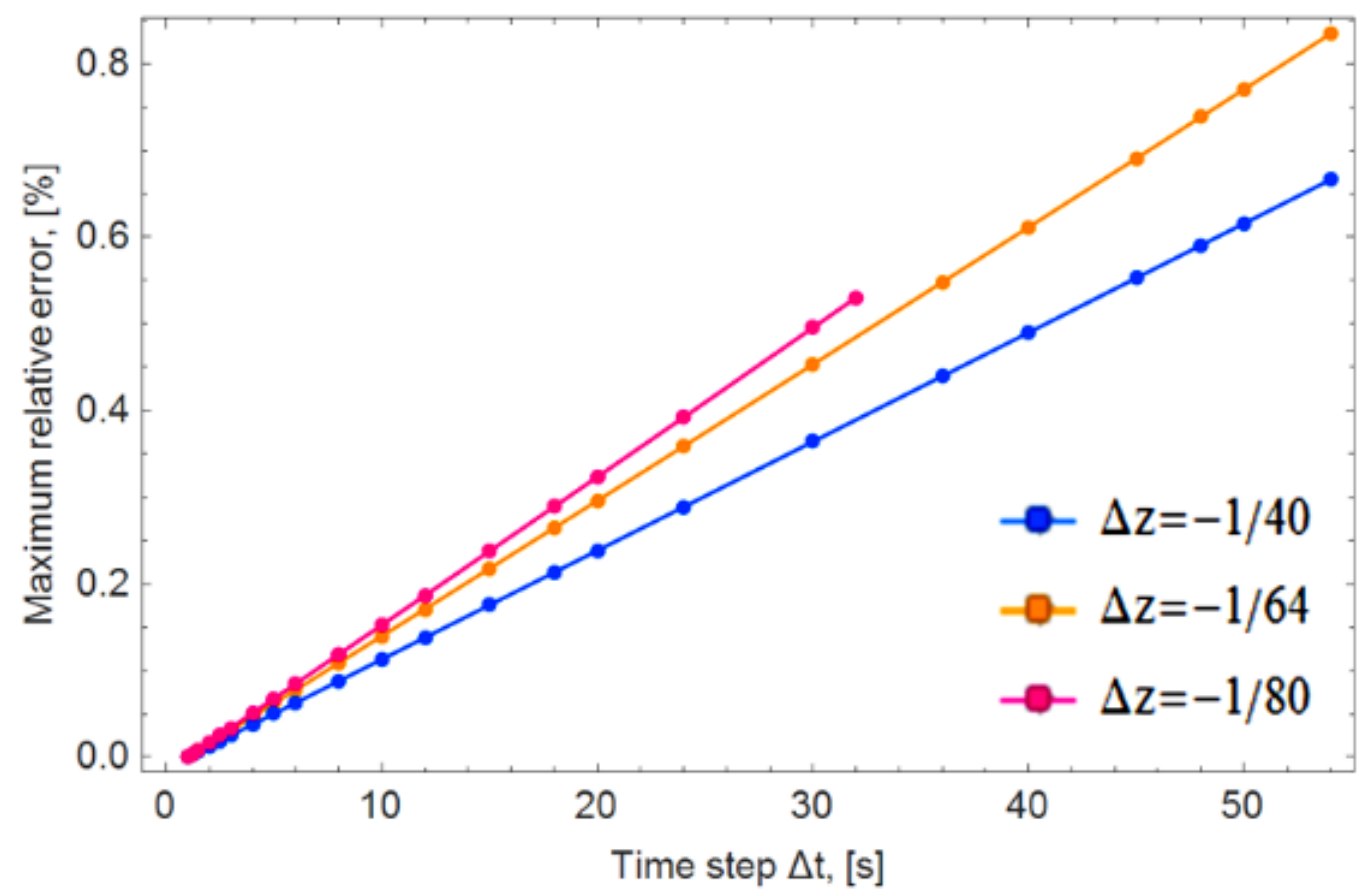

Figure 4. Maximum relative error as a function of the time step for three different spatial steps.

In similar models based on matric potential only (Pedrozo, Rosenberger, \& Schvezov, 2015), the instabilities occur for time steps larger than $26 \mathrm{~s}$, and with much larger relative errors of $25 \%$. This shows that the present model based on both, the degree of saturation and matric potential, is more stable and presents less error.

The relationship between CPU time versus maximum global error was plotted in Figure 5 for the same three-time steps of $-1 / 40,-1 / 64$, and $-1 / 80 m$ and a time step of one second. As observed and reported in 
the literature, the error decreases as CPU time increases. It should be noted that the unit of CPU time label is second, these results suggest that the present model presents a reasonable compromise among CPU time and global error.

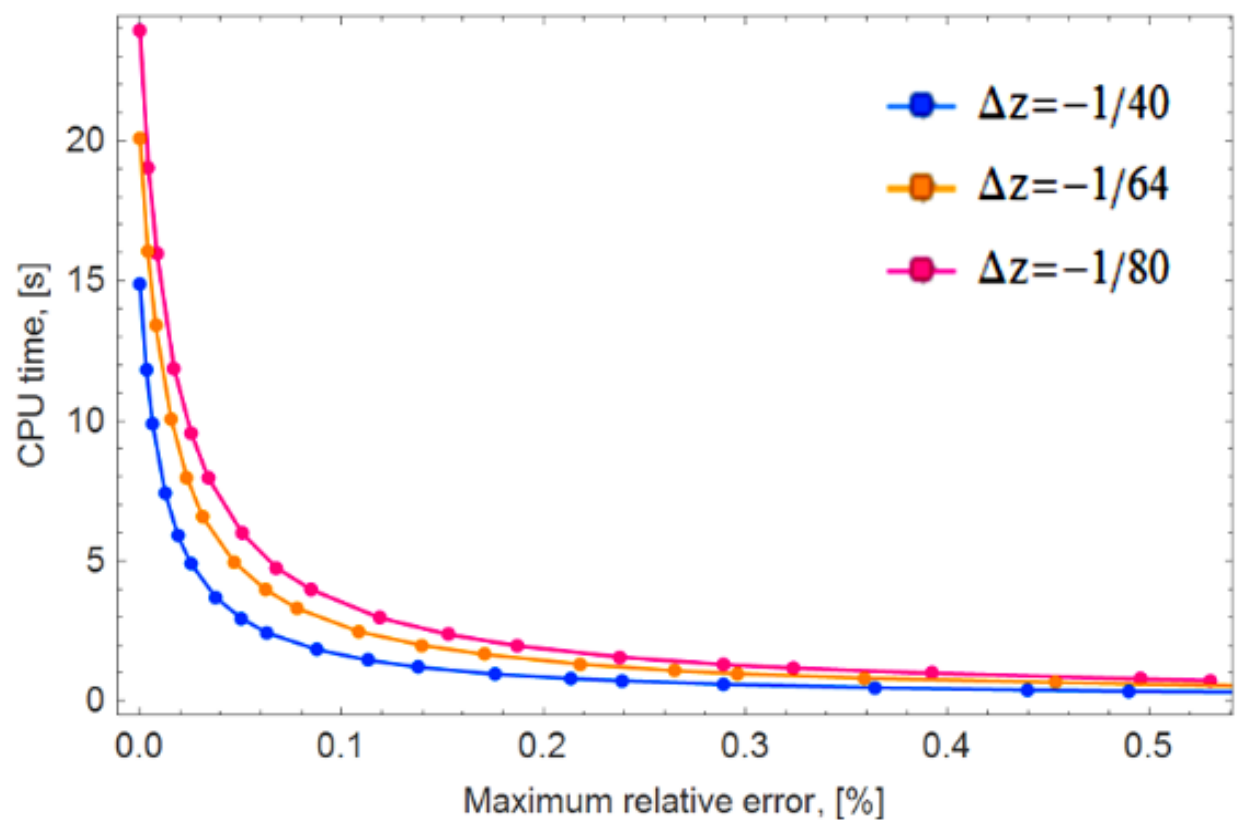

Figure 5. CPU time as a function of the maximum relative error for three different spatial steps.

A typical matric potential profile versus depth for the same three spatial step sizes are plotted in Figure 6, for a time step of one second and for an elapsed time of one day from the initial condition. It is observed that the three profiles strongly overlap. 
Tecnología y

Ciencias $₫$ Agua
2022, Instituto Mexicano de Tecnología del Agua

Open Access bajo la licencia CC BY-NC-SA 4.0

(https://creativecommons.org/licenses/by-nc-sa/4.0/)

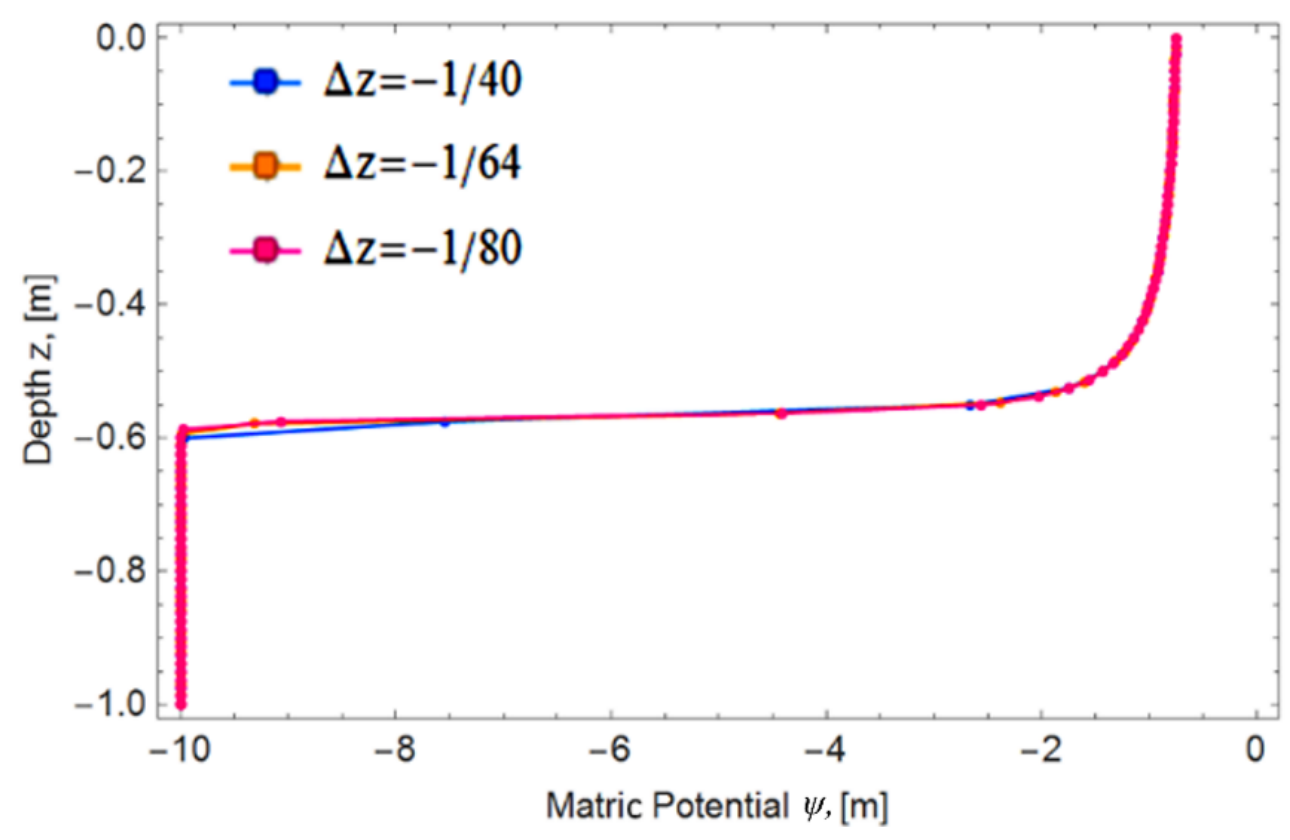

Figure 6. Humidity profile inside the soil, plots for the three different spatial steps (the plots are overlapping for this drawing resolution).

\section{Effect of the spatial step, $\Delta z$}

The model equations are developed by applying a mass balance in each domain element with a node in the center. The matric potential for each node is then an average value for each element. 
The comparison was made in the same portion of the domain, keeping track of the element portion and averaging the results'values for the smaller steps as shown in Figure 7.

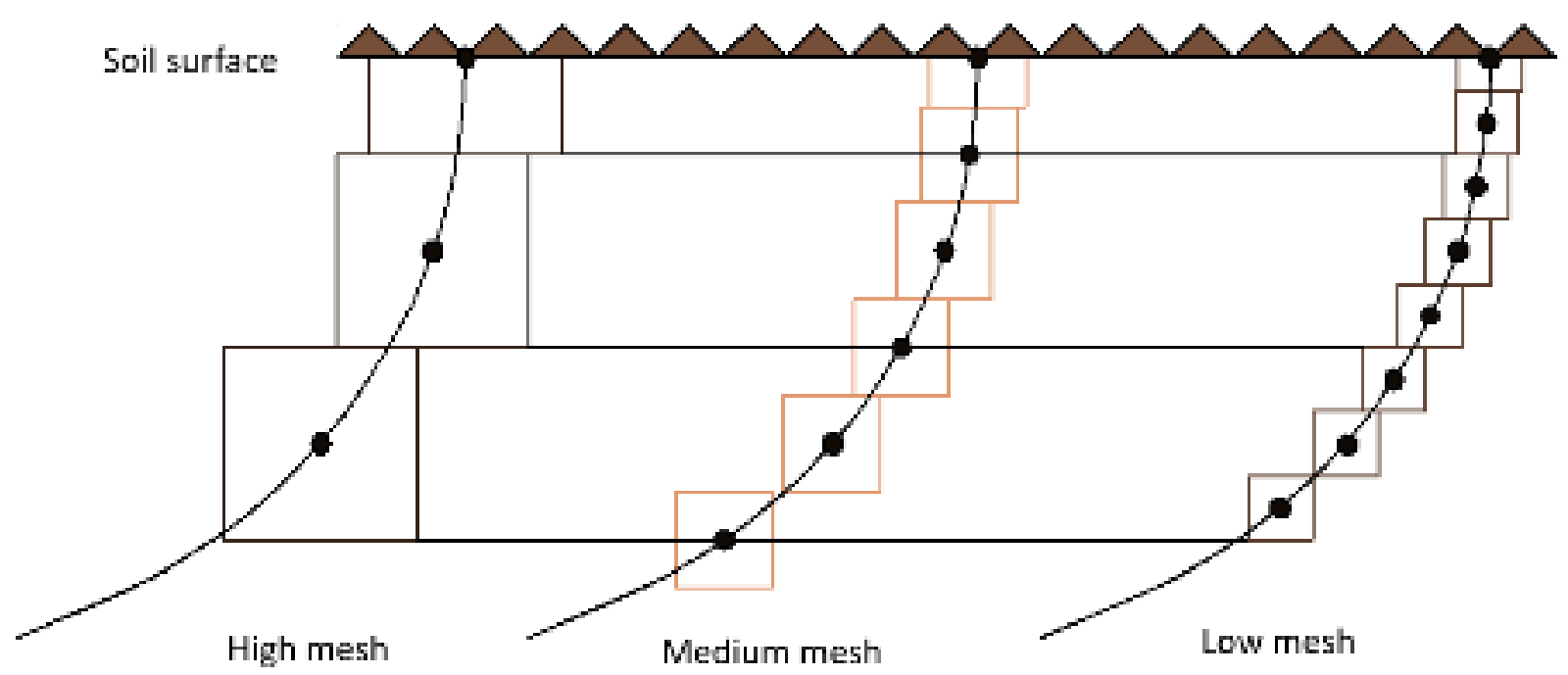

Figure 7. Node scheme for different meshes and its portion of domains representing.

The spatial steps employed in comparing the results are $-1 / 32$, $-1 / 64$, $-1 / 96,-1 / 128$, and $-1 / 192 \mathrm{~m}$; the smaller time steps results are used as a reference, considering that the finer the mesh more accurate the results are.

Three meshes are illustrated in Figure 7, and the results for the five meshes are shown in Figure 8, including maximum relative error and CPU 
Tecnología y

Ciencias $₫$ Agua
2022, Instituto Mexicano de Tecnología del Agua

Open Access bajo la licencia CC BY-NC-SA 4.0

(https://creativecommons.org/licenses/by-nc-sa/4.0/)

time as a function of the spatial step, $\Delta z$. It was observed that the error increases with spatial step in a non-linear relation; the effect of spatial step on CPU time is not strong as the maximum relative error in a whole interval of a few seconds, which makes the model suitable for calculations.

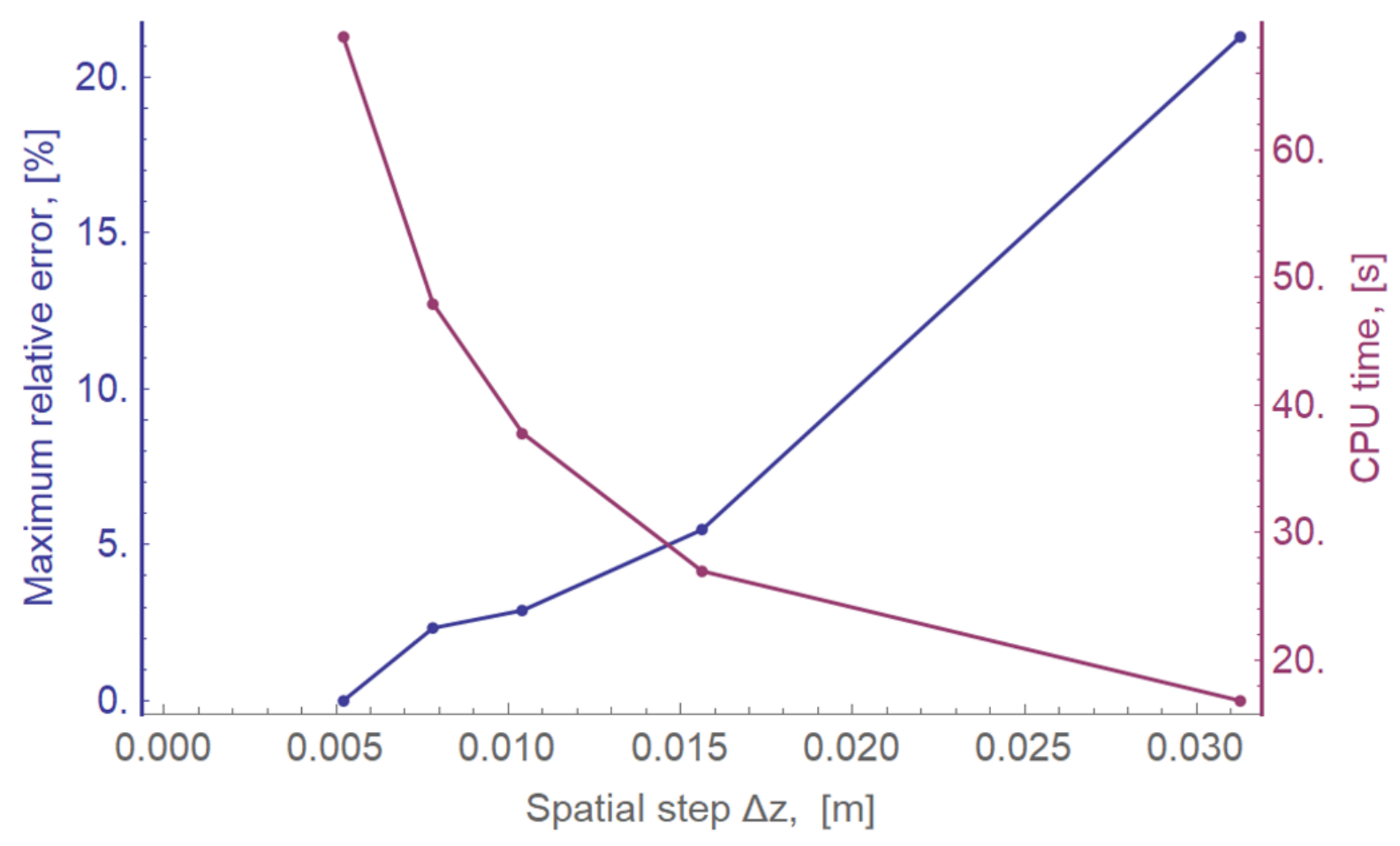

Figure 8. Effect of spatial step, for the same time step of 1 second, on the maximum relative error and CPU time. 


\section{Fourier analysis for convergence determination}

\section{Algebraic linearization}

The conditions for convergence depend on the values of the physical variables and the parameters of the simulation, such as spatial and time steps. The convergence interval for finite difference methods was studied using Fourier stability analysis; however, this technique was developed for linear equations only, which is not the case of the present model. Therefore, to apply Fourier stability analysis, the following process of algebraic linearization was applied.

First, let be:

$a_{i}^{j}=\frac{P K\left(\psi_{i}^{j}\right)-P K\left(\psi_{o}^{j}\right)}{\Delta z \cdot i}$

which gives: 
Tecnología y

Ciencias $₫$ Agua
2022, Instituto Mexicano de Tecnología del Agua

Open Access bajo la licencia CC BY-NC-SA 4.0

(https://creativecommons.org/licenses/by-nc-sa/4.0/)

$P K\left(\psi_{i}^{j}\right)=a_{i}^{j} \cdot \Delta z \cdot i+P K\left(\psi_{0}^{j}\right)$

$a_{i}^{j}$, given by Equation (12), is the slope of the secant of $P K(\psi)$ between the zero and the i-th nodes.

Using the Mualem-van Genuchten constitutive equation, the hydraulic conductivity can be written as:

$$
K\left(\psi_{i}^{j}\right) \cong \frac{K\left(\psi_{0}^{j}\right)-K\left(\psi_{M}^{j}\right)}{P K\left(\psi_{0}^{j}\right)-P K\left(\psi_{M}^{j}\right)} \cdot a_{i}^{j} \cdot \Delta z \cdot i+c t e
$$

where $M$ is the number of nodes, $\psi_{0}^{j}$ and $\psi_{M}^{j}$ are the boundary condition at the top and bottom surfaces of the domain, respectively.

On the other hand, $S e_{i}^{j}$ can be approximated by a Taylor expansion as:

$S e_{i}^{j} \cong\left(\left.\left(\frac{K(\psi) \cdot d \psi}{d S e}\right)\right|_{\max }\right)^{-1} \cdot \Delta z \cdot i \cdot a_{i}^{j}+S e_{0}^{j}$

where $K(\psi) \cdot d \psi / d S e$ was evaluated in the maximum and critical value (top surface) which may produce or initiate the instability. 
Defining the values of $\lambda$ and $\varepsilon$ by Equation (16) and Equation (17), respectively, and introducing equation (13) to (17) in the model Equation (10), a linear approximation of the model equation (10) is obtained, which is written as Equation (18):

$\left.\lambda=\left(K(\psi) \cdot \frac{d \psi}{d s e}\right)\right)_{\max } \frac{\Delta t}{\Delta z^{2} \cdot\left(\theta_{s}-\theta_{r}\right)}$

$\varepsilon=\frac{K\left(\psi_{0}^{j}\right)-K\left(\psi_{M}^{j}\right)}{P K\left(\psi_{0}^{j}\right)-P K\left(\psi_{M}^{j}\right)} \cdot \Delta z$

$a_{i}^{j+1}=a_{i}^{j}+\frac{\lambda}{i}\left(a_{i+1}^{j}(i+1)-2 a_{i}^{j} i+a_{i-1}^{j}(i-1)+0.5 \varepsilon\left(a_{i+1}^{j}(i+1)-a_{i-1}^{j}(i-1)\right)\right)$

In particular, $\lambda$ is a non-dimensional number which may be interpreted by analogy with the main simulation parameter in the solution of the heat equation by the finite difference method, which in that case is the product of the thermal diffusivity multiplied by the time step $\Delta t$, and divided by the square of the spatial step, $\Delta z$. In Equation (16), the expression $(K(\psi) \cdot d \psi / d S e)\left(\theta_{s}-\theta_{r}\right)^{-1}$ is the hydraulic diffusivity of the soil (Hillel, 1998), which relates the hydraulic conductivity and the soil's specific capacity, which is analogous to the thermal diffusivity. 
In the case of a linear partial derivative equation, convergence is analyzed using a Fourier stability analysis, known as Von Neumann analysis (Hirsch, 2007; Pletcher, Tannehill, \& Anderson, 2012). In that case, the model results are stable if the rounding error in the model equation decreases as iterations proceed.

In the present case, the values of $a_{i}^{j}$ must be consistent with the physical phenomenon that is; since the water must be transported from higher to lower values of the matric potential, the values of $a_{i}^{j}$ must decrease after each time step iteration. To follow its evolution, the function $G(\beta, i)$ is defined as an amplification factor and calculated as:

$G(\beta, i)=\frac{a_{i}^{j+1}}{a_{i}^{j}}$

Where:

$G(\beta, i)=1+\lambda\left(-2+\left(2+\frac{\varepsilon}{i}\right) \cos (\beta)\right)+\lambda\left(\frac{2}{i}+\varepsilon\right) \cdot I \cdot \sin (\beta)$

$|G(\beta, i)|=\sqrt{\left(1+\lambda\left(-2+\left(2+\frac{\varepsilon}{i}\right) \cos (\beta)\right)\right)^{2}+\left(\lambda\left(\frac{2}{i}+\varepsilon\right) \cdot \sin (\beta)\right)^{2}}$ 
where in Equation (19b), $I$ is the imaginary unit, and $\beta$ is a phase angle. Details of the procedure to obtain Equation (19b) are presented in Appendix A.

The amplification factor defined here is different from that defined in the literature (Pletcher et al., 2012), as the ratio between the rounding errors at time steps $j$ and $j+1$, which does not take into account the physical characteristic of the boundary problem, as it was done in Equation (20).

In an infiltration problem, where the Dirichlet boundary condition applies, the amplification factor must be less than 1 to be consistent with the physical phenomenon problem. Since $a_{i}^{j}$ is the gradient in the downward z-direction, at time $j$ of $P K(\psi)$, after each time step iteration, the downward water transport produce a reduction in the $P K(\psi)$ gradient, therefore $a_{i}^{j+1}$ will be less than $a_{i}^{j}$, and therefore $G(\beta, i)$ should always be less than one and at equilibrium tend to 1 . Values of $G(\beta, i)$ larger than 1 indicates that either the numerical calculations are unstable or divergent.

\section{Comparison between the approximation and the original function}


Equation (14) and Equation (15) are the approximating for $K\left(\psi_{i}^{j}\right)$ and $S e_{i}^{j}$, which original functions are given by Equation (3) and Equation (10), respectively.

The soil parameter $\alpha, q$, and $m$, for both the approximation and original function, are taken from the literature (Celia et al., 1990) for which the Mualem-van Genuchten equations were used $\left(\alpha=3.35 \mathrm{~m}^{-1}, q\right.$ $=2$ and $m=0.5$ ) for $K(S e)$ in Equation (3) as well as in Equation (14). The results are shown in Figure 9 for a simulation of one week. It was observed an excellent correlation between approximated and original values. 


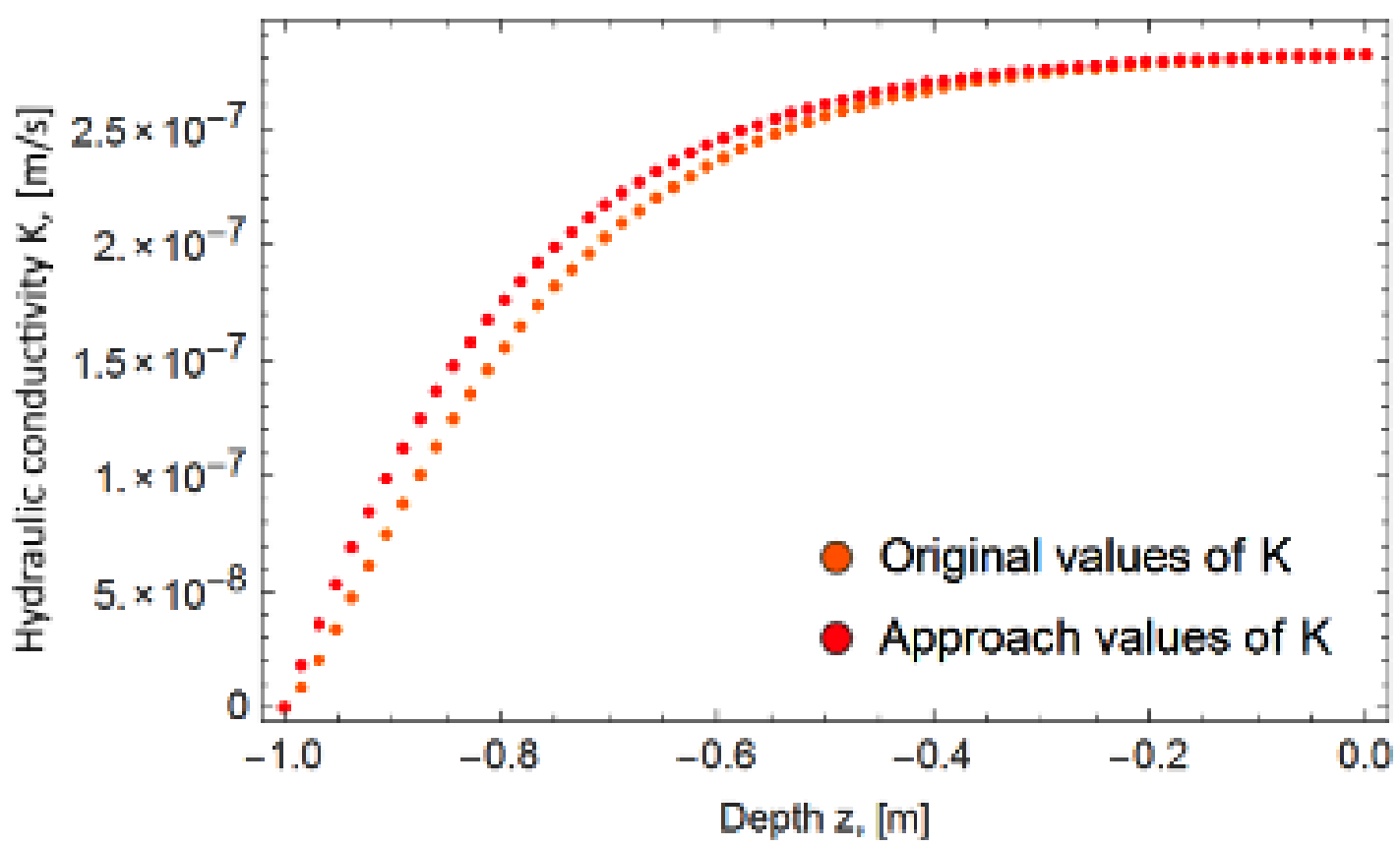

Figure 9. Comparison of the value of hydraulic conductivity versus depth, where actual values are calculated from the constitutive relationship (Equation (3)) and approach values calculated from Equation (14).

On the other hand, for the case of the saturation degree $S e$, the results are given by Equation (10) and its approximation given by Equation (15) are shown in Figure 10, also for a simulation time of one week, which was considered enough for wetting the lowest boundary of the domain. It is noted that the correlation is excellent for the upper part of the domain, which is wet, and not good for the lower part of the domain which is drier than the upper nodes. 


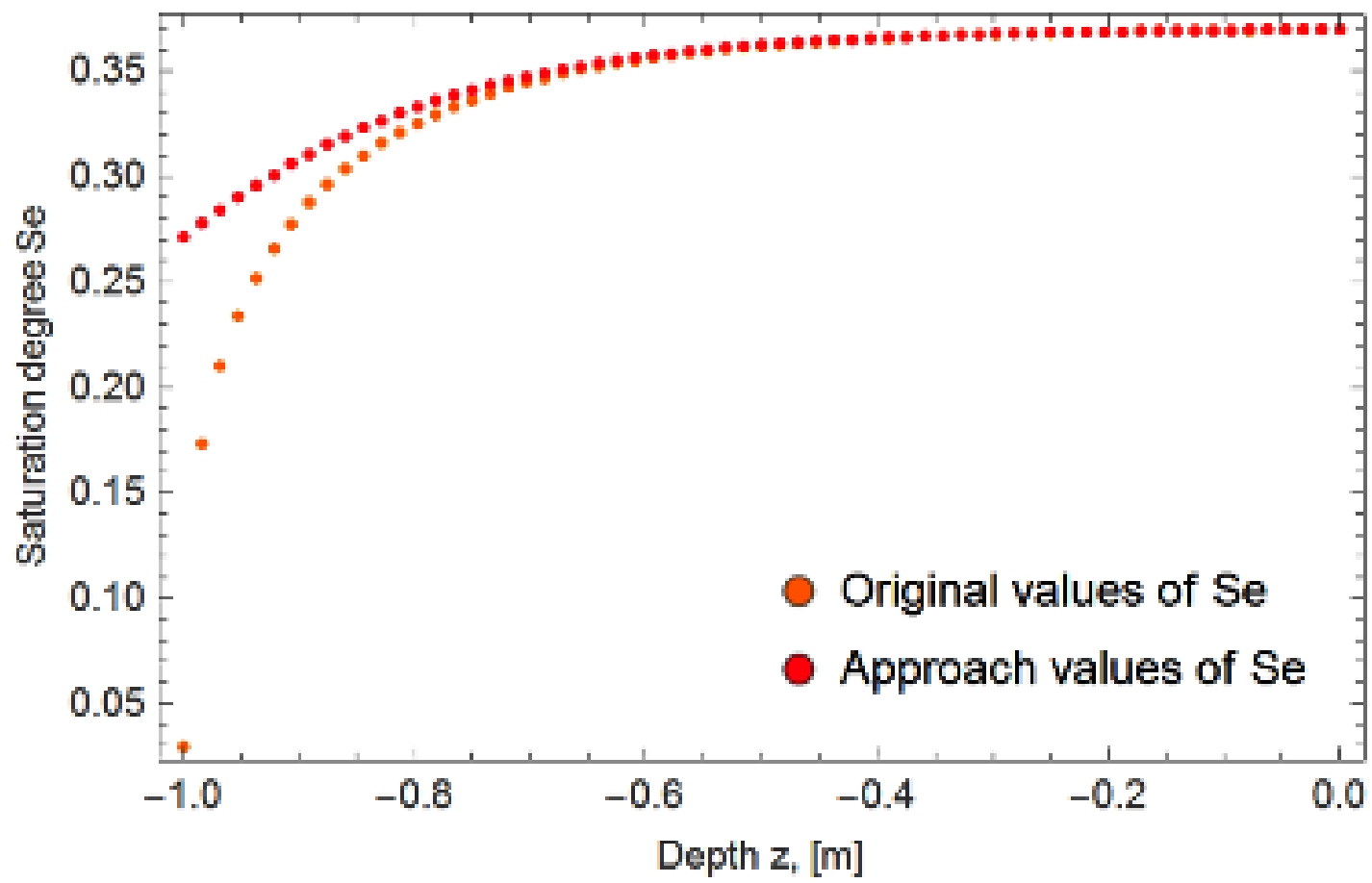

Figure 10. Comparison of the value of Se versus depth, where actual values are calculated from the finite difference scheme (Equation (10)) and approach values are calculated from Equation (15).

It should be noted that the approximation is accurate for the wet region which is the critical region for the stability analysis, and therefore the approximation given by Equation (15) is suitable for stability analysis. 
Tecnología y

Ciencias $₫$ Agua
2022, Instituto Mexicano de Tecnología del Agua

Open Access bajo la licencia CC BY-NC-SA 4.0

(https://creativecommons.org/licenses/by-nc-sa/4.0/)

\section{Results}

The amplification factor $G(\beta, i)$, as a function of the relation phase $(\beta)$, for different time steps and a spatial step size of $-1 / 64 \mathrm{~m}$ is shown in Figure 11a. The example corresponds to an infiltration problem with initial and boundary conditions as shown in Parameters and Validation, which results are obtained using the original set of equations (16), (17), and (20). The number of node $i$ is evaluated in 65 for all cases, due to the amplification factor increases with $i$, so the critical case was considered.
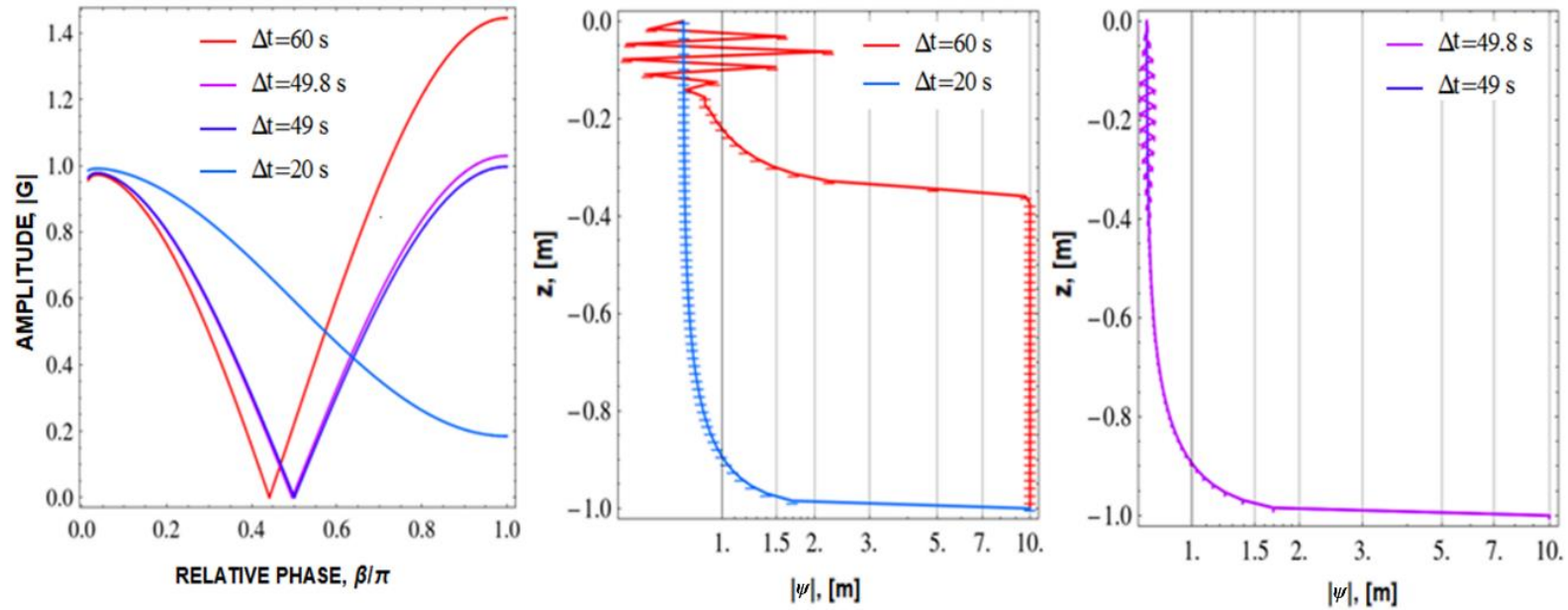

Figure 11. a) Damping factor versus relative phase considering 20,49, 49.8 and $60 \mathrm{~s}$ as time steps; (b) A stable ( $\Delta t=20 \mathrm{~s})$ and an unstable 
$(\Delta t=60 \mathrm{~s})$ simulations; (c) A stable $(\Delta t=49 \mathrm{~s})$ and an unstable $(\Delta t=$ $49.8 \mathrm{~s}$ ) simulation simulations close to the convergence threshold ( $G=$ 1); $\Delta z=-1 / 64 \mathrm{~m}$ for all cases. Reproduced from (Pedrozo et al., 2016), with the permission of AIP Publishing.

In Figure $11 \mathrm{a}$, it can be observed that $G(\beta, i)$ remains below 1 for the shorter time step of $20 \mathrm{~s}$ and $49 \mathrm{~s}$, and for longer steps of $49.8 \mathrm{~s}$ that is, only $0.8 \mathrm{~s}$ more, the values of $G(\beta, i)$ on relative phase values equal to 1 are larger than 1 for a few decimals, however, for a step of $60 \mathrm{~s}$ the values of $G(\beta, i)$ increases well above 1 for relative phase values larger than 0.7 .

The model results obtained for time step $20 \mathrm{~s}$ and $60 \mathrm{~s}$ clearly show stable and highly unstable behavior, respectively, as can be seen in Figure 11b. Moreover, the instabilities occur for the lower values of the depth $z$. The transition from stable to unstable behavior was remarkably sharp as shown in Figure 11c, where the profiles obtained for two-time steps of $49 \mathrm{~s}$ and $49.8 \mathrm{~s}$ show stable and unstable results, respectively, as predicted by the corresponding $G(\beta, i)$ values are shown in Figure $11 \mathrm{a}$.

From the above results, it may be concluded that the linearized Fourier stability analysis accurately predicts the onset of instability in the calculations, which may occur for even short time steps, and that the largest value of $G(\beta, i)$, or the instability, occurs for relative phase values near 1. 
In addition, a second data set was used to test the present method to determine if the simulation was stable. The reference problem was the infiltration of water in another sandy soil with the following parameters (Goh, 2017): $\theta_{s}=0.41 \mathrm{~m}^{3} / \mathrm{m}^{3}, \theta_{r}=0.065 \mathrm{~m}^{3} / \mathrm{m}^{3}, \alpha=7.5 \mathrm{~m}^{-1}, K s=1.23 .10^{-}$ $5 \mathrm{~m} . \mathrm{s}^{-1}, n=1.89$. The soil was initially with uniform humidity $\left(0.15 \mathrm{~m}^{3} / \mathrm{m}^{3}\right)$ in the whole domain with a top surface at constant high humidity $(0.4098$ $\left.\mathrm{m}^{3} / \mathrm{m}^{3}\right)$. The soil depth was $0.5 \mathrm{~m}$, and the spatial step was fixed at -0.001 $\mathrm{m}$.

The results of this simulation are shown in Figure 12. It can be observed that $G(\beta, i)$ remains below one for 4.357 milliseconds, which was the critical time step for the current simulation. When the time step was slightly increased at 4.4 milliseconds, it was observed that $G(\beta, i)$ was higher than one at a relative phase near to one, then it was observed in Figure $12 \mathrm{a}$ that the simulation becomes unstable at a simulation time of $1.76 \mathrm{~h}$. On the other hand, when the simulation was performed with a time step of 4.357 milliseconds, the simulation was stable, even at a simulation time of two hours, as Figure 12c shows. 

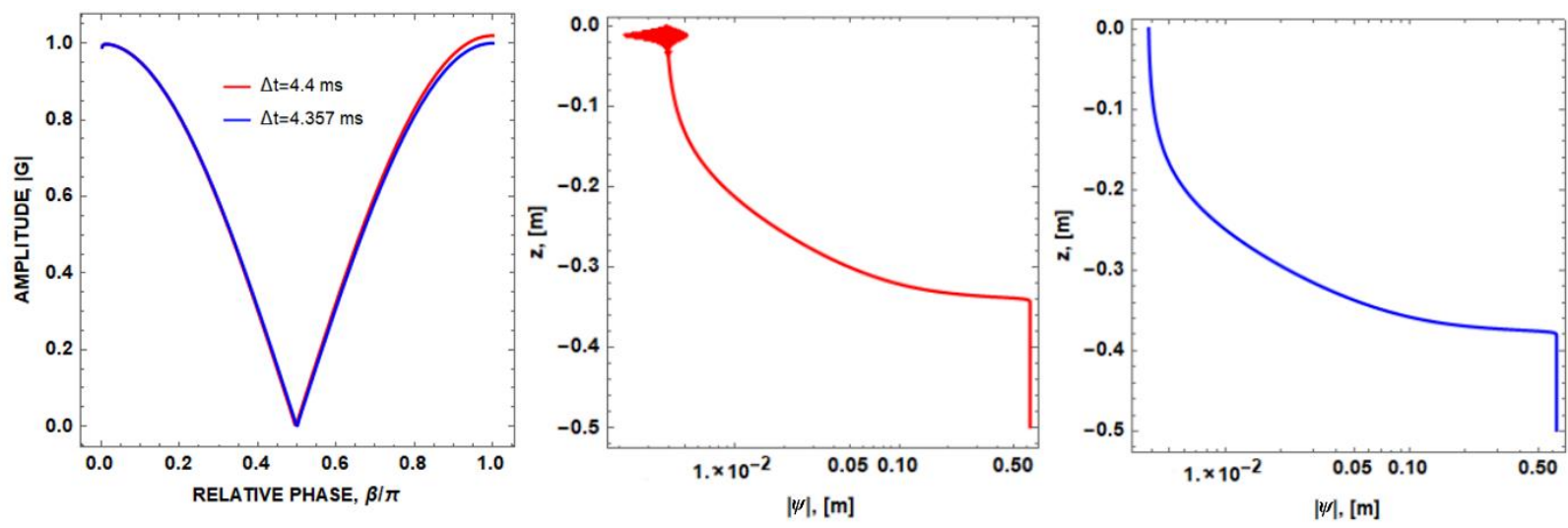

Figure 12. a) Damping factor versus relative phase for two-time steps; 4.357 and 4.4 milliseconds; b) simulations were obtained for time steps of: 4.4 milliseconds (unstable); (c) simulations were obtained for a time step close to the convergence limit ( $G=1$ ) using 4.357 milliseconds (stable). In all cases, the spatial step is $-0.001 \mathrm{~m}$.

\section{Sensitivity to the boundary condition}

The present infiltration model also shows a high sensitivity to the applied boundary conditions at the top and wet surfaces. The soil reported by Celia (Celia et al., 1990) was taken to the current analysis. Figure 13a shows the amplification factor $G(\beta, i)$ as a function of the relative phase for four different values of $\psi_{0}$ at the top surface; $-1 m,-0.75 m,-0.74 m$, 
and $-0.5 \mathrm{~m}$. The spatial step and time step used are $-1 / 64 \mathrm{~m}$ and $49 \mathrm{~s}$ respectively, that is, near the instability values for $\Delta t$. In Figure $13 \mathrm{~b}$, it was observed that instability increases as the top surface was more humid. The model was stable for a dryer condition; instability starts for intermediate values of humidity and becomes highly unstable for the highest humidity surface. The numerical instability might be because the higher the humidity, the faster the diffusion of humidity, and the larger values of gradients associated. The diffusivity was related to the parameter $\lambda$ which value increases with diffusivity. Therefore $\lambda$ becomes one of the critical parameters to predict the start of instability.
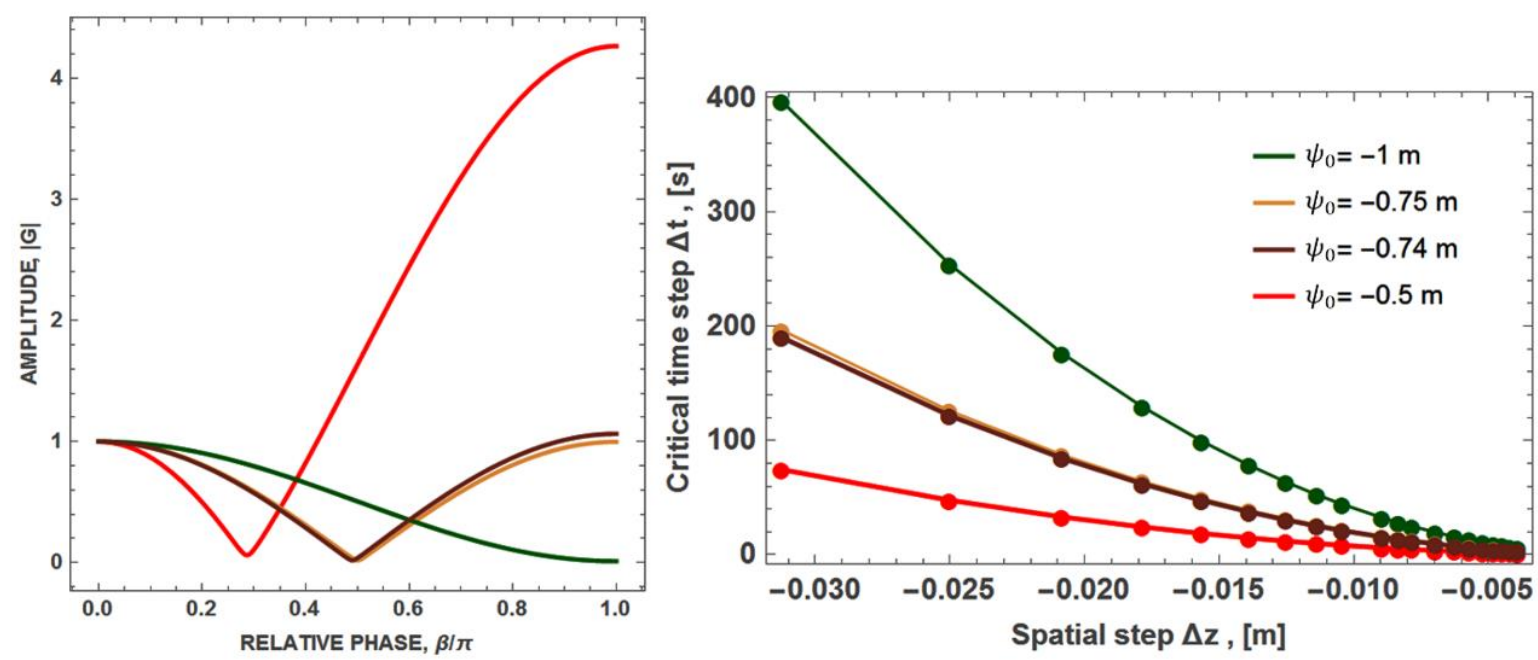

Figure 13. Maximum time step vs. spatial steps for three upper boundary conditions, a high wet $(h=-0.5 \mathrm{~m})$, a medium wet ( $h$ $=-0.75 \mathrm{~m})$ and a low wet $(h=-1 \mathrm{~m})$. 
On the other hand, the model was insensitive concerning the condition at the lower or dry boundary. This result may be because the hydraulic conductivity and the function $P K(\psi)$ were insensitive for the low matric potentials.

At this point, it was possible with the analysis proposed here, to establish the critical time step as a function of spatial step and boundary condition by using Equation (20). This was done for a spatial step of $-1 / 64$ $\mathrm{m}$ and the same three previous boundary conditions which results are shown in Figure 13b. It was observed that as the humidity increases the model was more sensitive and that in all cases the critical points are near the top or wet surface; also that the relation between critical time step versus spatial is not linear. As a result, problems with high humidity conditions will require shorter time steps and then longer CPU time.

\section{Results of the generalization}


In the previous section, the linear stability analysis was applied in two infiltration problems proposed in the literature (Celia et al., 1990) and (Goh, 2017). The objective of the present section is to expand the application of the procedure to infiltration in other soils with different characteristics using the Richards equation; that is different values of the parameters $\lambda$ and $\varepsilon$ defined by Equation (16) and Equation (17), respectively.

Analyzing the Equation (19b), for the amplification factor $G(\beta, i)$, it was observed that it depends on the parameters $\lambda$ and $\varepsilon$ and two variables; the phase angle $(\beta)$ and the node number $(i)$.

Given the values of $\lambda$ and $\varepsilon$, the stability condition is that the value of $G(\beta, i)$ must be less than one for the whole interval from 0 to 1 of the phase angle $\beta$ and all nodes $i$. Since the maximum value of $G(\beta, i)$ is located at node $i=M$, if its value is less than one, the stability condition was satisfied for all the other nodes.

Before finding the stability regions, it was necessary to perform a sensitivity analysis of $G(\beta, i)$ with respect to the parameters $\lambda, \varepsilon$, and $M$. As can be observed in Equation (19b), $G(\beta, i)$ depends on the parameters $\lambda$ and $\varepsilon$, and the variables are the phase angle $(\beta)$ and the node number $i$; which for this analysis can be fixed on $i=M$. The effect of each parameter was analyzed as follows; in the first place, $\lambda$ is taken as a variable with fixed values of $\varepsilon=-2$ and $M=100$; in the second place, $\varepsilon$ is taken as a variable with fixed values of $\lambda=0.5$ and $M=100$; and in third place, $M$ is variable and $\lambda=0.5$ and $\varepsilon=-2$. The three cases are plotted in 
Figure 14a, Figure 14b, and Figure 14c, respectively. The coordinate axes are the real and the imaginary components of $G(\beta, i)$, and the region of stability is painted in yellow.
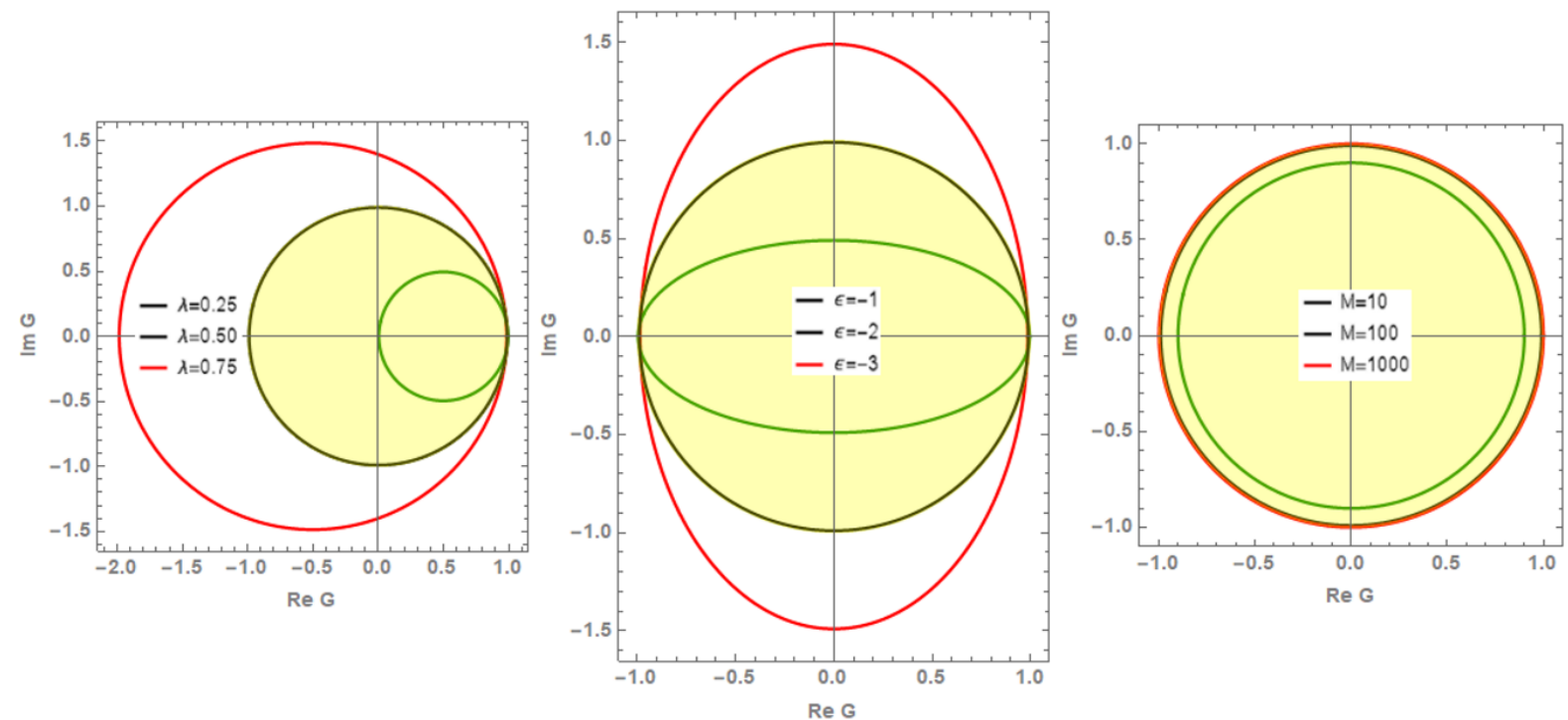

Figure 14. Polar representation of the amplification factor: a) $\lambda$ is variable; $\varepsilon=-2$; $M=100$; b) $\lambda=0.5$; $\varepsilon$ is variable; $M=100$; c) $\lambda=0.5$; $\varepsilon=-2 ; M$ is variable.

In Figure $14 a$ the component for a fixed $\lambda$ are circumferences whose radius increases with $\lambda$, particularly for $\lambda=0.5$, it is noted that the circumference is centered in the origin of the coordinates and this shows that all the points inside the circle have amplification values less than 1. Moreover, the circle corresponding to the circumference of the values with 
$\lambda=0.25$ is inside the larger circle, which indicates that the region of stability of the model is given by all the points inside the circle corresponding to a value of $\lambda \leq 0.50$. In addition, for the three cases, the center is in the real axis at a distance of the origin equal to 1-2 $\lambda$.

In Figure $14 \mathrm{~b}$ it can be seen that for the three values of $\varepsilon$ the geometrical patterns are ellipses with a longer axis in the imaginary component of $G(\beta, i)$ when the $\varepsilon \leq-2$ and in the direction of the real component for $\varepsilon \geq-2$, with a transition at $\varepsilon=-2$ where the figure is a circumference. In all cases, the center is located in origin and for $\varepsilon=-2$ the radius of the circumference is 1 , which defines a circle of stability for all internal points and therefore all the values of $\varepsilon \geq-2$ since all ellipses are inside the circle.

Finally, taking $M$ as a variable the geometrical places in all cases are the circumferences centered in the origin and radius that increase with the value of $M$. However, the increase of the radius decreases exponentially as $M$ increases. In the three cases, the radius of the circle is less than 1 , indicating that the method is stable regardless of the value of $M$.

The sensitivity analysis shows that the main parameters affecting the value of the amplification factor $G(\beta, i)$ are $\lambda$ and $\varepsilon$ and that the effect of $M$ is negligible. The combined effect on the module of the amplification factor of $\lambda$ and $\varepsilon$, is shown in Figure $15 a$, for $M=100$ nodes, where the level curves for three values of the amplification factorare shown; $1,1.25$ and 1.5 , indicating the region of stability for $|G|<1$ in blue and the 
contours of transition to unstable region. The region of stability shows two different behaviors, in the first place, for values of $-2 \leq-\varepsilon \leq-0$ the stability does not depend on $\varepsilon$ but only on $\lambda$ such that the method is stable for values $\lambda \leq 0.5$.
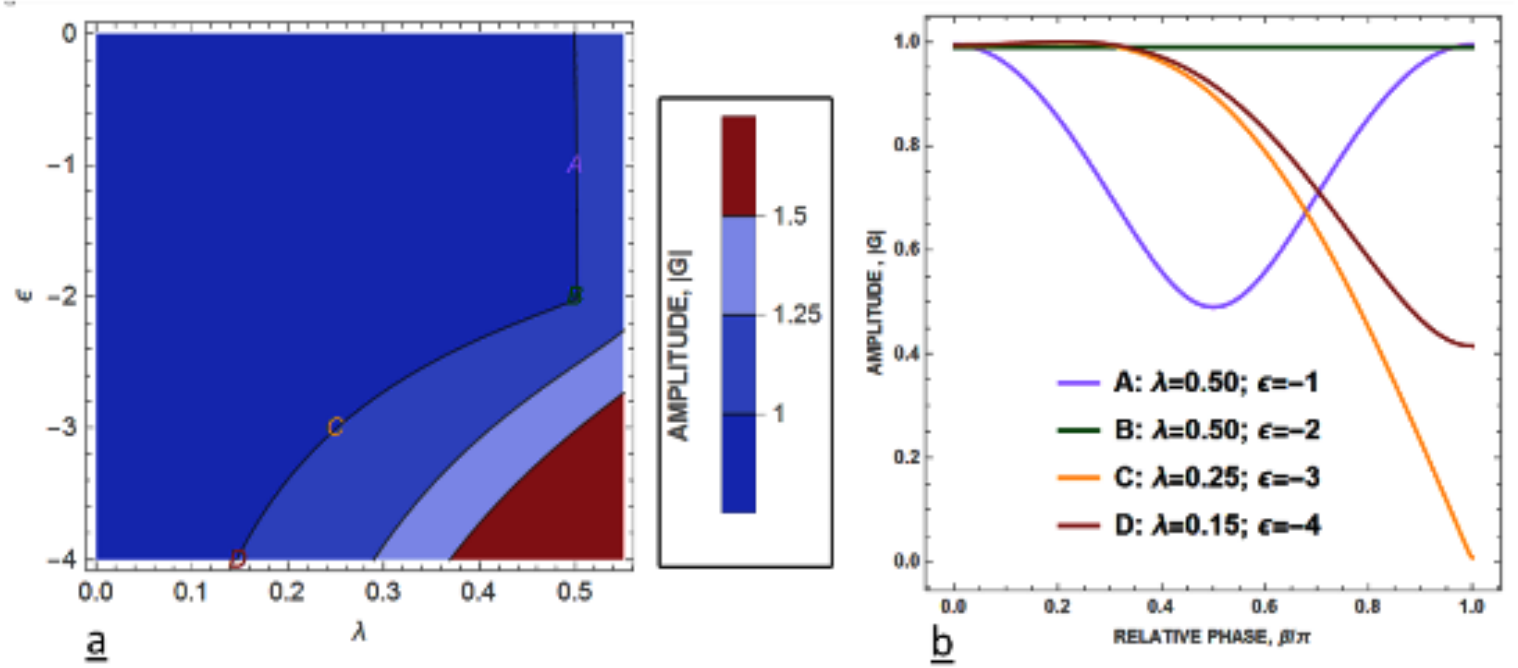

Figure 15. a). Maximum values of amplification factor as a function of parameters $\lambda$ and $\varepsilon$. b). Module of amplification factor versus relative phase.

For values of $\varepsilon<-2$, the stability depends on both $\lambda$ and $\varepsilon$ (line $C$ ). This would be associated with the above sensitivity analysis in which the geometrical places for the real and imaginary components of $G(\beta, i)$ are ellipses in which part of the surface area may stay outside the circle of stability (Figure 14b). 
To continue with the analysis, the values of $|G|$ were plotted as a function of the relative phase $(\beta / \pi)$ for four points, which is shown in Figure $15 \mathrm{a}$, which are in the limit of stability (maximum $|G|$ is equal to $1) ; A, B, C$ and $D$ for four specific values of $\lambda$ and $\varepsilon$ as indicated in Figure $15 \mathrm{~b}$. For $\mathrm{A}$ with $\lambda=0.5$ and $\varepsilon=-1,|G|$ presents two maximum points at $\beta / \pi=0$ and $\beta / \pi=1$, being the latter the global maximum. For point $B$ with $\lambda=0.5$ and $\varepsilon=-2,|G|$ has a value of practically 1 and is insensitive to the relative phase. For point $C$ with $\lambda=0.25$ and $\varepsilon=-3,|G|$ lightly increases from $\beta / \pi=0$ to a maximum value at $\beta / \pi \sim 0.2$ and then sharply decreases. For point $D$ with $\lambda=0.15$ and $\varepsilon=-4$, the behavior of $|G|$ with $\beta / \pi$ is similar as in the case of the point $C$.

From the above analysis, it is possible to develop the following general conditions for the stability of the method for solving the Richards equation by a finite difference method, which can be seen in the Appendix.

For $-2 \leq \varepsilon \leq 0$, from Equation (19b), when the relative phase tends to 1 independently of the absolute value of $M$. Under this condition in Equation (19b), the cosine function tends to -1 , and the sine function tends to 0 . Therefore, the following stability condition was derived:

$\left|1-4 \lambda-\frac{\varepsilon \lambda}{M}\right| \leq 1$

Considering that $-2 \leq-\varepsilon \leq-0$, Equation (21) was simplified as: 
Tecnología y

Ciencias $₫$ Agua
2022, Instituto Mexicano de Tecnología del Agua

Open Access bajo la licencia CC BY-NC-SA 4.0

(https://creativecommons.org/licenses/by-nc-sa/4.0/)

$0 \leq \lambda \leq \frac{2}{4+\frac{\varepsilon}{M}}$

In the case of negligible values of $\varepsilon / M$ that are obtained for low values of $\varepsilon$ or large values of $M$, Equation (22) can be further simplified as follows, and consistently with curve A in Figure 15a :

$0 \leq \lambda \leq \frac{1}{2}$

For the region with a transition given by curve $C$, in Figure $15 \mathrm{a}$, that is values of $\varepsilon \leq-2$ and shown in Figure $15 \mathrm{~b}$ for point $\mathrm{C}$, it was observed that the maximum occurs for a relative phase of $\beta / \pi \approx 0.2$ rather than $\beta / \pi \approx 1$, which makes difficult the derivation of a specific relation for the lower limit of the convergence or stability region of Figure $15 \mathrm{a}$.

\section{Conclusions}


In this work, we proposed an explicit finite difference-based method to solve the Richards equation, which formulation employs both, the degree of saturation and the matric potential. The algorithm profits form the problem structure to reduce the problem size and consequently, the CPU time. The model was validated by using a case study from the literature, resulting in an excellent agreement.

Since explicit methods present inherently a convergence threshold that depends on the simulation parameters, $\Delta t$, and $\Delta z$, we developed an algebraic linearization that was capable of predicting accurately the stability limits. We applied the Fourier transform analysis to the linearized equations to determine if the simulation was stable. Finally, we expand the stability analysis beyond the case study, performing a sensibility analysis and establishing the stability conditions for a general case.

\section{Appendix A: Derivation of Equation (19b)}

From the linear approximation of the model (18), the function $a_{i}^{j}$ was approached by using the Fourier series, as it is shown in Equation (A.1), 
Tecnología y

Ciencias $₫$ Agua
2022, Instituto Mexicano de Tecnología del Agua

Open Access bajo la licencia CC BY-NC-SA 4.0

(https://creativecommons.org/licenses/by-nc-sa/4.0/)

Equation (A.2), Equation (A.3), and Equation (A.4), where $k_{m}$ is defined in Equation (A.5):

$a_{i}^{j+1}=a_{i}^{j}+\frac{\lambda}{i}\left(a_{i+1}^{j}(i+1)-2 a_{i}^{j} i+a_{i-1}^{j}(i-1)+0.5 \varepsilon\left(a_{i+1}^{j}(i+1)-a_{i-1}^{j}(i-1)\right)\right)$

$a_{i}^{j}=b_{m}(j) e^{I \cdot k_{m} \cdot i \cdot \Delta z}$

$a_{i}^{j+1}=b_{m}(j+1) e^{r \cdot k_{m} \cdot i \cdot \Delta z}$

$a_{i-1}^{j}=b_{m}(j) e^{I \cdot k_{m}(i-1) \Delta z}$

$a_{i+1}^{j}=b_{m}(j) e^{l \cdot k_{m} \cdot(i+1) \Delta z}$

$k_{m}=\frac{m \cdot \pi}{M \cdot \Delta z}$

where $m=0,1,2 \ldots M$. 
Introducing Equation (A.1), Equation (A.2), Equation (A.3), and Equation (A.4), in the linear approximation of the model (18), it is possible to write the following expression:

$$
\begin{aligned}
& b_{m}(j+1) e^{I \cdot k_{m} \cdot i \cdot \Delta z}=b_{m}(j) e^{I \cdot k_{m} \cdot i \cdot \Delta z}+b_{m}(j) e^{I \cdot k_{m} \cdot i \cdot \Delta z} \cdot \frac{\lambda}{i} \cdot\left(-2 i+i\left(e^{I \cdot k_{m} \cdot \Delta z}+\right.\right. \\
& \left.e^{-I \cdot k_{m} \cdot \Delta z}\right)+\left(e^{I \cdot k_{m} \cdot \Delta z}-e^{-I \cdot k_{m} \cdot \Delta z}\right)+0.5 \varepsilon\left(i\left(e^{I \cdot k_{m} \cdot \Delta z}-e^{-I \cdot k_{m} \cdot \Delta z}\right)+\left(e^{I \cdot k_{m} \cdot \Delta z}+\right.\right. \\
& \left.\left.\left.e^{-I \cdot k_{m} \cdot \Delta z}\right)\right)\right)
\end{aligned}
$$

Now applying the above Equation (A.6) on the definition of $G(\beta, i)$ given by the Equation (19a), applying the Euler identity, it was obtained the following expression:

$$
\begin{aligned}
& G(\beta, i)=1+\frac{\lambda}{i}\left(-2 i+i\left(2 \cos \left(k_{m} \Delta z\right)\right)+\left(2 I \sin \left(k_{m} \Delta z\right)\right)+0.5 \varepsilon\left(i\left(2 I \sin \left(k_{m} \Delta z\right)\right)+\right.\right. \\
& \left.\left.\left(2 \cos \left(k_{m} \Delta z\right)\right)\right)\right)
\end{aligned}
$$

Doing the necessary simplifications and algebraic operations and considering that $k_{m} \Delta z=\beta$, it was obtained the expression (19b), shown below: 
Tecnología y

Ciencias $\approx$ Agua
2022, Instituto Mexicano de Tecnología del Agua

Open Access bajo la licencia CC BY-NC-SA 4.0

(https://creativecommons.org/licenses/by-nc-sa/4.0/)

$G(\beta, i)=1+\lambda\left(-2+\left(2+\frac{\varepsilon}{i}\right) \cos (\beta)\right)+\lambda\left(\frac{2}{i}+\varepsilon\right) I \sin (\beta)$

\section{Appendix B: The condition of stability for $-2 \leq-\varepsilon$ $\leq-\mathbf{0}$}

Performing analysis for the extreme critical case (relative phase is one), giving by the Equation (21), the Equation (B.1) and Equation (B.2) are written and analyzed below:

If $\frac{\beta}{\pi}=1$ and $G(\beta, i) \leq 1\left|1-4 \lambda-\frac{\varepsilon \cdot \lambda}{M}\right| \leq 1$

$1-4 \lambda-\frac{\varepsilon \cdot \lambda}{M} \leq 1$

$1-4 \lambda-\frac{\varepsilon \cdot \lambda}{M} \geq-1$ 
Rearranging Equation (B.1), was obtained Equation (B.3), which could be simplified as Equation (B.4):

$\frac{-\varepsilon \cdot \lambda}{M} \leq 4 \lambda$

$\varepsilon \geq-4 M$

On the other hand, Equation (B.2), follows Equation (B.5):

$\lambda\left(-4-\frac{\varepsilon}{M}\right) \geq-2$

Equation (B.4) implies that the left member of (B.5) must be negative since $\lambda$ is a positive parameter (see Equation (16)); thus it follows the convergence condition (23):

$\lambda \leq \frac{2}{4+\frac{\varepsilon}{M}}$

Then, Equation (22) together with equation (B.4) are mathematically sufficient conditions to satisfy Equation (21). 
On the other hand, Equation (22) depends on $M$ (maximum number of nodes) and $\varepsilon$, and it was more restrictive in deeper nodes due to the fact that $\varepsilon$ is a negative parameter (see Equation (17)). However, a clear trend is presented in (22), when the number of nodes increases, and it tends to infinity, in that case, could be obtained Equation (23).

$\lambda \leq \frac{1}{2}$

\section{References}

Baker, D. L. (2000). A Darcian integral approximation to interblock hydraulic conductivity means in vertical infiltration. Computers and Geosciences, 26(5), 581-590. Recovered from https://doi.org/10.1016/S0098-3004(99)00129-6

Berardi, M., Difonzo, F., Vurro, M., \& Lopez, L. (2018). The 1D Richards' equation in two layered soils: A Filippov approach to treat discontinuities. Advances in Water Resources, 115, 264-272. Recovered from https://doi.org/https://doi.org/10.1016/j.advwatres.2017.09.027

Berardi, M., \& Vurro, M. (2016). The numerical solution of Richards' equation by means of method of lines and ensemble Kalman filter. Mathematics and Computers in Simulation, 125, 38-47. Recovered from https://doi.org/10.1016/j.matcom.2015.08.019 
Canelón, D., \& Darío, J. (2003). Análisis de estabilidad numérica del esquema implícito de los cuatro puntos basado en diferencias finitas. Geoenseñanza, 8(2), 105-113. Recovered from https://www.redalyc.org/html/360/36080209/

Caviedes-Voullième, D., Garcl, P., \& Murillo, J. (2013). Verification, conservation, stability and efficiency of a finite volume method for the 1D Richards equation. Journal of Hydrology, 480, 69-84. Recovered

from https://doi.org/https://doi.org/10.1016/j.jhydrol.2012.12.008

Celia, M. A., Bouloutas, E. T., \& Zarba, R. L. (1990). A general massconservative numerical solution for the unsaturated flow equation. Water Resources Research, 26(7), 1483-1496. Recovered from https://doi.org/10.1029/WR026i007p01483

Goh, E. G. (2017). Philip's Semi-Analytical Solution on Water Infiltration into Unsaturated Soil based on Van Genuchten Equation. In: Proceedings of the 12th International Conference on Latest Trends in Engineering and Technology (ICLTET'2017), the 7th International Conference on Agricultural, Chemical, Biological and Environmental Sciences (ACBES'2017), Kuala Lumpur, Malaysia.

Gyrya, V., Lipnikov, K., Manzini, G. \& Svyatskiy, D. (2014). M-Adaptation in the mimetic finite difference method. Mathematical Models and Methods in Applied Sciences, 24(08), 1621-1663. Recovered from https://doi.org/10.1142/S0218202514400053 
Hillel, D. (1998). Environmental soil physics: Fundamentals, applications, and environmental considerations. San Diego, USA: Elsevier.

Hills, R. G., Porro, I., Hudson, D. B., \& Wierenga, P. J. (1989). Modeling one-dimensional infiltration into very dry soils: 1. Model development and evaluation. Water Resources Research, 25(6), 1259-1269.

Recovered

from https://doi.org/10.1029/WR025i006p01259

Hirsch, C. (2007). Numerical computation of internal and external flows: The fundamentals of computational fluid dynamics. Oxford, UK: Butterworth-Heinemann.

Jeltsch, R., \& Nevanlinna, O. (1981). Stability of explicit time discretizations for solving initial value problems. Numerische Mathematik, 37(1), 61-91. Recovered from https://doi.org/10.1007/BF01396187

Lipnikov, K., Moulton, D., \& Svyatskiy, D. (2016). New preconditioning strategy for Jacobian-free solvers for variably saturated flows with Richards' equation. Advances in Water Resources, 94, 11-22. Recovered from ttps://doi.org/10.1016/j.advwatres.2016.04.016

Miller, C. T., Dawson, C. N., Farthing, M. W., Hou, T. Y., Huang, J., Kees, C. E., ..., \& Langtangen, H. P. (2013). Numerical simulation of water resources problems: Models, methods, and trends. Advances in Water Resources, 51, 405-437. Recovered from https://doi.org/10.1016/j.advwatres.2012.05.008 
Miranda, J. H., Duarte, S. N., Libardi, P. L., \& Folegatti, M. V. (2005). Simulação do deslocamento de potássio em colunas verticais de solo não-saturado. Engenharia Agrícola, 25(3), 677-685. Recovered from https://doi.org/10.1590/S0100-69162005000300013

Mualem, Y. (1976). A new model for predicting the hydraulic conductivity of unsaturated porous media. Water Resources Research, 12(3), 513-522.

Recovered

from https://doi.org/10.1029/WR012i003p00513

Pedrozo, H. A., Rosenberger, M. R., \& Schvezov, C. E. (2016). Stability analysis of the solution of the one-dimensional Richards equation by the finite difference method. In: AIP Conference Proceedings (vol. 1738). Recovered from https://doi.org/10.1063/1.4952244

Pedrozo, H. A., Rosenberger, M. R., \& Schvezov, C. E. (2015). Comparación entre modelos en diferencias finitas aplicados a la infiltración en suelos. Revista de Ciencia y Tecnología, (23), 36-44. Recovered from http://www.scielo.org.ar/scielo.php?script=sci_arttext\&pid=S1851 $-75872015000100006$

Pletcher, R. H., Tannehill, J. C., \& Anderson, D. (2012). Computational fluid mechanics and heat transfer. Florida, USA: CRC Press.

Richards, L. A. (1931). Capillary conduction of liquids through porous mediums. Journal of Applied Physics, 1(5), 318-333. Recovered from https://doi.org/10.1063/1.1745010 
Romano, N., Brunone, B., \& Santini, A. (1998). Numerical analysis of onedimensional unsaturated flow in layered soils. Advances in Water Resources, 21(4), 315-324. Recovered from https://doi.org/10.1016/S0309-1708(96)00059-0

Saucedo, H., Zavala, M., \& Fuentes, C. (2015). Diseño de riego por melgas empleando las ecuaciones de Saint-Venant, y Green y Ampt. Tecnología y ciencias del agua, 6(5), 103-112. Recovered from http://www.scielo.org.mx/scielo.php?script=sci_arttext\&pid=S200 7-24222015000500008

Schlüter, S., Vanderborght, J., \& Vogel, H. J. (2012). Hydraulic nonequilibrium during infiltration induced by structural connectivity. Advances in Water Resources, 44, 101-112. Recovered from https://doi.org/10.1016/j.advwatres.2012.05.002

Solin, P., \& Kuraz, M. (2011). Solving the nonstationary Richards equation with adaptive hp-FEM. Advances in Water Resources, 34(9), 10621081.

Recovered

from

https://doi.org/10.1016/j.advwatres.2011.04.020

Szymkiewicz, A., \& Helmig, R. (2011). Comparison of conductivity averaging methods for one-dimensional unsaturated flow in layered soils. Advances in Water Resources, 34(8), 1012-1025. Recovered from https://doi.org/10.1016/j.advwatres.2011.05.011

van Genuchten, M. T. (1980). A closed-form equation for predicting the hydraulic conductivity of unsaturated soils. Soil Science Society of 
America Journal, 44(5), 892. Recovered from https://doi.org/10.2136/sssaj1980.03615995004400050002x

Warrick, A. W. (1991). Numerical approximations of Darcian flow through unsaturated soil. Water Resources Research, 27(6), 1215-1222. Recovered from https://doi.org/10.1029/91WR00093

Wendland, E., \& Pizarro, M. de L. P. (2010). Modelagem computacional do fluxo unidimensional de água em meio não saturado do solo. Engenharia Agrícola, 30(3), 424-434. Recovered from https://doi.org/http://dx.doi.org/10.1590/S010069162010000300007

Yuste, S. B., \& Acedo, L. (2005). An explicit finite difference method and a new von Neumann-type stability analysis for fractional diffusion equations. SIAM Journal on Numerical Analysis, 42(5), 1862-1874. Recovered from https://doi.org/10.1137/030602666 